\title{
Children pillion rider safety awareness among motorcycle users in Malaysia
}

\begin{abstract}
Motorcycle is one of the more popular modes of transport for Malaysian people due to its low price and easy usability. This paper reviews the current safety initiatives undertaken to address the need to enhance children safety whilst riding as pillion on motorcycles and suggest possible remedial action to counter the possible lack of awareness for child pillion riders. A search was undertaken of all the major database of articles. Articles related to children's safety systems, children related injuries, children related accident data, available laws and legislation were reviewed. There is a greater need for the stricter enforcement of safety laws in Malaysia due to the fact that the accident statistics show a large percentage of motorcycle accidents involve pillion riding children. However, enforcement of laws in developing countries is not easy and one has to start at the root of the problem, i.e. the parents and adults who ride these children as pillion on motorcycles. This paper highlights the need for new safety initiatives and programmes to be undertaken by the government, law agencies and non-governmental organisations for parents and adults to understand the importance of their children safety while riding on motorcycles. Engineering countermeasures and intervention are needed to protect these vulnerable users. Besides the helmet, a device capable of providing some sort of protection to the child whilst riding pillion should be designed and developed.
\end{abstract}

Keyword: Motorcycle safety; Pillion rider; Children; Malaysia; Awareness and measures 